\title{
Self-Esteem and Quality of Life in mild cerebral palsy : a cross cultural study
}

\author{
Rowena Sait ${ }^{1}$ \\ ${ }^{1}$ Post Graduate Student, Department of Psychology, Maniben Nanavati Women's College, Mumbai \\ E-mail-rsait30@gmail.com
}

\begin{abstract}
Self esteem has been reported to be low in individuals with physical disabilities like cerebral palsy. This in turn is known to affect their quality of life. The purpose of this study was to investigate self-esteem and quality of life (QOL) among individuals with mild spastic cerebral palsy in a cross cultural study across India and United States of America. 60 participants aged twelve to twenty five years (30 from India, 30 from USA) were subjects of the study. They were administered the Rosenberg Self-Esteem Scale and the World Health Organization-Quality Of Life Brief Scale to measure the study variables. Data was collected using the method of convenience sampling. The results were analysed using multivariate analysis of variance. As hypothesized, there was no significant difference between self-esteem and quality of life among cerebral palsy adolescents in India and Unites States of America. Results suggested that the type of cerebral palsy has an effect on self-esteem but not quality of life. The country of one's residence also showed no effect on one's self esteem and
\end{abstract} quality of life.

Key words: cerebral palsy, self esteem, quality of life, spastic.

\section{INTRODUCTION}

Cerebral palsy is a neurological condition that affects the development of movement and posture it is often combined with disturbances of sensation, perception, cognition, and behaviour. It occurs in about 2.1 per 1,000 live births [1]. The first descriptions of the cerebral palsy is mentioned in the work of Hippocrates in the 5th century BC. There have been extensive studies of the condition that began dated back in the19th century by William John Little [2]. Cerebral palsy is not an infectious or contagious disease with about $2 \%$ of all cases having a genetic cause and most of the cases are diagnosed during an early age rather than adolescent or adulthood [3].The most important feature of cerebral palsy is a movement disorder but it is often shows other combined symptoms like difficulties with thinking, learning, feeling, communication and behaviour [4]. Cerebral palsy can be seen as early as during the neonatal stages of developmental between 6 to 9 months, where there is preferential use of limbs, asymmetry, or any kind of gross motor developmental delay is seen. The resulting conditions of this can also include seizures, epilepsy, apraxia, dysarthria or other 
communication disorders, eating problems, sensory impairments, intellectual disability, learning disabilities, urinary incontinence, faecal incontinence, and/or behavioural disorders [5]. One of the main causes of cerebral palsy is due to damage occurring to the developing brain. This damage can occur anytime during the pregnancy, delivery, the first month of life, or at times less commonly during early childhood [6]. Cerebral palsy where spasticity or muscle tightness also commonly known as spastic cerebral palsy it is the most common type of cerebral palsy occurring in almost $70 \%$ or more of all cases. In spastic cerebral palsy the muscle tightness is the almost exclusive impairment that is present [7].

Spastic diplegia is historically also known as Little's Disease. It is a form of cerebral palsy that manifests tightness or stiffness in the muscles of the lower extremities of the humanbody, usually those of the legs, hips and pelvis [8]. Spastic hemiplegia is a neuromuscular condition of spasticity that results in the muscles on one side of the body being in a constant state of contraction or muscle tightness. It is the also known as the one-sided version of spastic diplegia. About 20 to $30 \%$ of patients who suffer from cerebral palsy are suffering from spastic hemiplegia [9]. Spastic quadriplegia, also known as spastic tetraplegia, is a subset of spastic cerebral palsy that affects all four limbs that is both arms and legs of the human body. Spastic quadriplegia affects all four limbs but the severity of stiffness or paralysis can differ, as in one arm could be stiffer than the other [10].

\section{Self-Esteem}

Self-esteem is a term used in psychology to describe an individual's overall emotional self- evaluation of his or her own worth. It is an outlook that one has of themselves as well as the attitude that they have towards themselves. Self-esteem is an amalgamation of one's beliefs and emotions such as triumph, despair, pride and shame. Smith and Mackie define it by saying "The self-concept is what we think about the self; self-esteem, is the positive or negative evaluations of the self, as in how we feel about it" [11]. Self-esteem is also known as an evaluative dimension of the self that includes feelings of worthiness, prides and discouragement. One's self-esteem is also closely associated with self-consciousness [12]. It is a belief that a person has which represents their own judgments of their worthiness. American psychologist Abraham Maslow included self-esteem in his hierarchy of needs. He described that there are two different forms of esteem: the need for respect from others, and the need for self-respect, or inner self-esteem. Respect from others includes recognition, acceptance, status, and appreciation, and is assumed to be more fragile and much easily lost than one's inner self-esteem. According to Maslow, without the fulfilment of the self-esteem need individuals unable to grow and obtain self-actualization and therefore individuals will be driven to seek it [14].

\section{Quality of Life}

Quality of life is an individual's general well-being as well as the well-being of society. Quality of life covers a wide range of contexts that include the fields of international development, politics and employment. One should not confuse quality of life with standard of living and it differs on the premise that standard of living is measured primarily on income. The standard indicators for quality of life include not only wealth and employment but also the environment, physical and mental health, education, recreation, leisure time, and social belonging [15].

Unlike per capita growth or standard of living, both of which can be measured in financial terms, it is hard to make an objective evaluation or a long-term 
measurement of the quality of life experienced by any nation or by any other groups of people. [16] Researchers in recent times have started to distinguish two aspects of an individual's personal well-being: Emotional well-being, where the individuals are asked about the quality of their daily emotional experiences, how frequent and intense the experiences are of, for example, joy, stress, sadness, anger, and affection and life evaluation, where the individual are asked to think about their life in general and evaluate it against a scale. These kinds of systems and scales of measurement have been in use for some time. Research has also attempted to examine the relationship between quality of life and productivity [17].

A study reviewed the quality of life and health related quality of life among cerebral palsy adolescents compared with normative population. The apparent trends were adolescents with cerebral palsy reported a lower quality of life and health-related quality of compared to normative population but not in all the areas of well-being [18]. Another study looked at the relationship between the functioning and quality of life for children with cerebral palsy. It was the children's self-report about their functioning, disability, pain and feelings, physical health and participation, disability. A higher variance in functioning was reported on the physical domains as compared to the psychosocial domains. It showed that children with cerebral palsy having poor functioning tend to report having a high psychosocial quality of life score [19]. A study conducted on self-esteem of cerebral palsy adolescents with nondisabled adolescents. Results showed that boys with cerebral palsy have higher self-esteem scores as compared to girls with cerebral palsy. Adolescent girls with cerebral palsy report having lower physical self-esteem when compared to the scores of nondisabled boys and girls. Adolescent girls with cerebral palsy also reported lower social self-esteem as compared to boys with cerebral palsy and nondisabled adolescent girls. Adolescent boys with cerebral palsy had scores almost similar to the scores of nondisabled adolescent boys and girls [20].

A longitudinal study was conducted on the self-esteem of 22 adolescents with cerebral palsy till adulthood. The scores were compared with those of nondisabled adolescents. They were each matched by age, sex, schools and intelligence quotients. The study was conducted over a period of seven years. As adolescents all the other groups scored significantly higher on the various domains of self-esteem, personal, physical and social, as compared to adolescents girls with cerebral palsy. As adults none of the groups were significantly different from the other. The self-esteem scores of male subjects with cerebral palsy in adolescent and adulthood were similar to the scores of the males from the nondisabled groups. Personal relationships and experiences were identified as the factors that lead to the changes in self-esteem [21].

\section{METHODOLOGY}

The purpose of this study was to investigate self-esteem and quality of life among individuals with mild spastic cerebral palsy (quadriplegia/hemiplegia/diplegia) in a cross cultural study across India and United States of America. There are two independent variables, type of cerebral palsy with three levels (quadriplegia/hemiplegia/diplegia) and country of residence (India and United States of America). The two dependent variables are self-esteem and quality of life. 


\section{Hypotheses}

1) There will be no difference in the self-esteem scores of individuals with mild spastic diplegic, hemiplegic and quadriplegic cerebral palsy.

2) There will be no difference in the quality of life scores of individuals with mild spastic diplegic, hemiplegic and quadriplegic cerebral palsy.

3) There will be no difference in the self-esteem scores of individuals with mild spastic cerebral palsy in India and the United States of America.

4) There will be no difference in the quality of life scores in individuals with mild spastic cerebral palsy in India and the United States of America.

Demographic details of each participant was collected at the time of testing. The details were inclusive of information about their cerebral palsy spasticity diagnosis and the location of their residence. Each participant was given the Rosenberg's Self-Esteem Scale [22] and the WHO Quality of Life Scale- BREF [23]. The participants answered the questionnaires at their own convenience. The research is a $2 \times 3$ within subject or repeated measures design with each participant undergoing the same levels of the variables. (self-esteem and quality of life). The scores obtained on self-esteem and quality of life was tabulated within the categories of type of cerebral palsy spasticity (hemiplegia/diplegia/quadriplegia) and location (India/United States of America) and further analysed for statistically significant results. Only individuals, between the ages of twelve to twenty four years were considered for this study. Purposive sampling was used as a method of data collection. The study used self-report demographic sheets for its independent variables and self-report scales as part of its research for dependent variables self-esteem and quality of life. Hindi and English both versions of the scale were made available to participants so as they could answer in the language they feel most comfortable.

\section{Rosenberg's Self-Esteem Scale}

The Rosenberg Self-Esteem Scale is a test that comprises of 10 items that measure the individual's overall self-esteem. The 10satements relate to the person's overall self-worth and acceptance. The answers for the items range from strongly agree to strongly disagree on a four point rating scale. Reliability correlation of at least 0.8 has been reported. Criterion validity is found to be at 0.55 [22].

\section{WHO Quality of Life-BREF}

The WHOQOL-BREF test consists of 26 items. The total quality of life score is broken down into four domains; physical health, psychological health, social relationships, and environment. It assesses the individual's perceptions in the context of their culture and value systems, and their personal goals, standards and concerns. The internal consistency of the four domains of the WHO-QOL-BREF ranged from 0.66 to 0.8 [23].

\section{RESULTS}

The mean and SD values for the effect of self-esteem on type of spastic cerebral palsy was $15.10 \pm 3.40$ for diplegia. For hemiplegia it was $14.58 \pm 3.115$ and for quadriplegia it showed a value of $13.35 \pm 2.719$. The value of quality of life on type of spastic cerebral palsy for diplegia was 191.02 \pm 52.587 , for hemiplegia was $191.68 \pm 60.641$ and for quadriplegia was $155.76 \pm 51.486$ respectively. The mean and SD 
for effect of self-esteem on country of residence for India was $14.59 \pm 3.227$ while for United States was $14.11 \pm 3.124$. The mean and SD for the effect of quality of life on the country of residence was $188.78 \pm 61.692$ for India and $169.22 \pm 48.997$ for United States.

Table 1 - Effect of country and type of CP

\begin{tabular}{|ccccccc|}
\hline Effect & Value & F & $\begin{array}{c}\text { Hypothesis } \\
\text { df }\end{array}$ & Error df & Significance \\
\hline Intercept & $\begin{array}{c}\text { Wilks' } \\
\text { Lambda }\end{array}$ & 0.043 & 73.597 & 2.000 & 66.000 & 0.000 \\
\hline Country & $\begin{array}{c}\text { Wilks' } \\
\text { Lambda }\end{array}$ & 0.943 & 2.005 & 2.000 & 66.000 & 0.143 \\
\hline $\begin{array}{c}\text { Type of } \\
\text { CP }\end{array}$ & $\begin{array}{c}\text { Wilks' } \\
\text { Lambda }\end{array}$ & 0.892 & 1.938 & 4.000 & 132.000 & 0.108 \\
\hline $\begin{array}{c}\text { Country } \\
\text { and } \\
\text { CP type }\end{array}$ & $\begin{array}{c}\text { Wilks' } \\
\text { Lambda }\end{array}$ & 0.966 & 0.577 & 4.000 & 132.000 & 0.680 \\
\hline
\end{tabular}

Multiple analysis of variance was used to examine the relationship between each dependent variable in the study. Results suggested that the type of spasticity and country has an effect on the self-esteem of individuals with mild spastic cerebral palsy whereas the type of spasticity and country has no effect on the quality of life of individuals with mild spastic cerebral palsy. For self-esteem the results were found to be significant but for quality of life the results were found to be non significant. A normality test was first run for the sample of seventy three participants. Results showed nonnormally distributed data for variables type of spasticity of mild cerebral palsy adolescents and quality of life and normally distributed data for self-esteem and country. A non-parametric test known as Kruskal-Wallis test was run for self-esteem and quality of life among types of cerebral palsy spasticity and country of residence. A nonparametric test was run as the data for all the variables was not normally distributed. Results suggested that the spasticity of cerebral palsy does have an effect on selfesteem but does not have an effect on quality of life. Also the country of residence of those with mild spastic cerebral palsy does not have an effect on self-esteem andquality of life.

Graph 1 - The estimated marginal means of self-esteem of the types of spasticity in India and the United States of America.

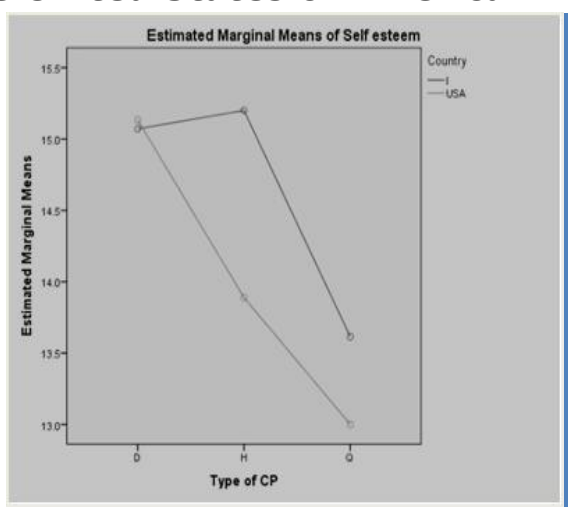


The graph 1 shows the plots for self-esteem of individuals with mild spastic diplegic, hemiplegic and quadriplegic cerebral palsy from India and United States of America. Where India shows higher self-esteem scores as compared to UnitedStates of America. Self-esteem scores for both countries is the highest for diplegic cerebral palsy followed by spastic hemiplegic cerebral palsy and the lowest scores for self-esteem for both countries was found for spastic quadriplegic cerebral palsy.

\section{Graph 2 - The estimated marginal means of total quality of life of the types ofspasticity in India and U.S.A.}

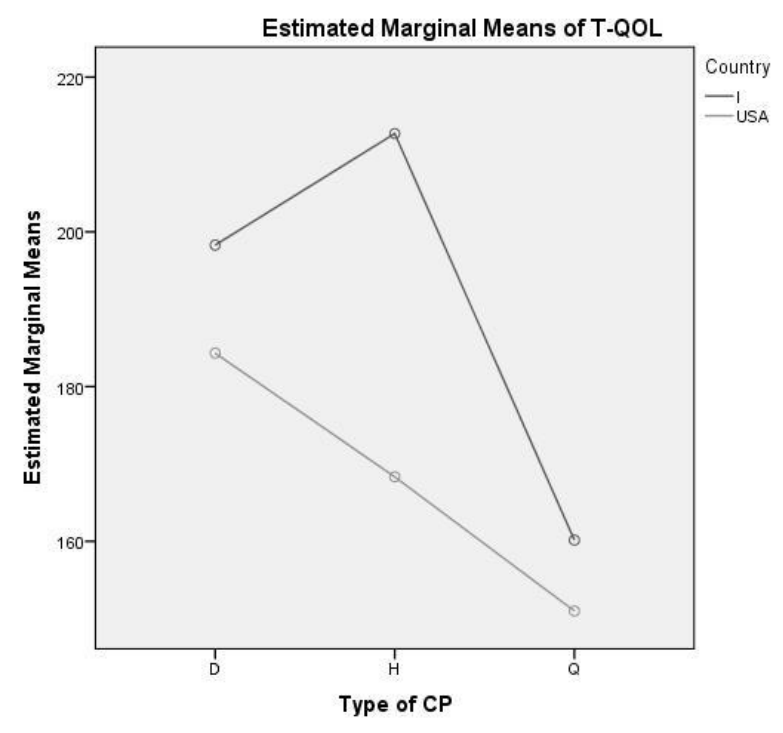

The graph 2 shows the plots for quality of life of individuals with mild spastic diplegic, hemiplegic and quadriplegic cerebral palsy adolescents from India and United States of America. When compared the quality of life scores for India are higher than the quality of life scores of United States of America and the self-esteem scores of spastic quadriplegic cerebral palsy adolescents or both countries is the lowest. In India spastic hemiplegic cerebral palsy showed the highest score on the quality of life scale whereas in United States of America spastic diplegic cerebral palsy showed the highest scores on the quality of life scale. Based on these findings we conclude that there was a difference found in the self-esteem scores of individuals with mild spastic diplegic, hemiplegic and quadriplegic cerebral palsy therefore rejecting the null hypothesis. There was a no difference found in the quality of life scores of individuals with mild spastic diplegic, hemiplegic and quadriplegic cerebral palsy thus we retain the null hypothesis. There was no difference found in the self-esteem scores of individuals with mild spastic cerebral palsy in India and in United States of America thus retaining the null hypothesis. There was no difference found in the quality of life scores of individuals with mild spastic cerebral palsy in India and in United States of America therefore retaining the null hypothesis.

\section{DISCUSSION}

The purpose of this research was to investigate self-esteem and quality of life in individuals with varying spasticity in diagnosed cerebral palsy residing in different countries, India and United States of America. As hypothesized there was no difference in the self-esteem and quality of life scores of individuals with mild cerebral palsy from India and United States of America. There was a difference found in the 
scores of the self-esteem of individuals from India and United States of America with varying spasticity in cerebral palsy, however there was no difference reported in the quality of life among those varying in spasticity in diagnosed cerebral palsy. An additional analysis was carried out by looking at the means for self-esteem for India and for United States of America and was found to be 14.59 (SD 3.237) and 14.11 (SD 3.124) respectively. Even though miniscule, there is a difference showing India reporting a higher self-esteem score than United States of America. The mean for quality of life for India was 188.78 (SD 61.692) and U.S.A was 169.22 (SD 48.997) where again individuals from India reported a higher quality of life as compared to United States of America. Previous research has always studied those diagnosed with cerebral palsy in comparison with normative population within the same country, and results showed that those without cerebral palsy reported having a higher self-esteem and quality of life. Studies also compared self-esteem of individuals across different ethnicities but from the same country. The present study compared the scores on selfesteem and quality of life with those diagnosed with mild spastic cerebral palsy from India and United States of America. A look at the graphs showed that both self-esteem and quality of life in both India and United States of America was the lowest for those diagnosed with quadriplegia, which is spasticity in all four limbs. The highest reported self-esteem and quality of life for both India and United States of America was for those diagnosed with diplegia, which is spasticity in the lower extremities of the body. A reason for this could be that the severity of paralysis is the least in diplegia as compared to hemiplegia or quadriplegia where half the body and all four limbs are affected receptively. For both variables, self-esteem and quality of life were higher for individuals with mild spastic cerebral palsy in India as compared to United States of America.

These results could be an implication of the results of past research which is that as a society India is more collectivistic in nature while United States of America is more individualistic in nature. India is more group reliant while United States of America has a more self-sufficient structure. When one is diagnosed with a disability, support from the immediate environment, strong social support systems are essential and helps the individual cope in multiple ways. In India family is given more importance whereas in United States of America the individual is held higher. The Indian family/society structure is built in a way where there is a division of responsibilities within primary support care which at times extends to secondary and tertiary family, individuals are more household oriented and there are possibilities of more social interactions as compared to United States of America where the individual and individualistic needs are held above those of the society. A study conducted had suggested that humans had felt more supported secure and happier when they got to work together and also when they got to help each other out in collective environments. One of the important findings in the study were that people felt happy and satisfied not only by being around others and spending time with them or $y$ doing things with them collectively but by also doings thing for the other person, by being pro-social [24]. This finding can be remotely linked to the current study thus explaining the marginally higher means of the self-esteem and quality of life scores of individuals with spastic cerebral palsy from India when compared to the United States of America. 


\section{REFERENCES}

1. Oskoui M, Coutinho F, Dykeman J, Jetté N, Pringsheim T. An update on the prevalence of cerebral palsy: a systematic review and metaanalysis. Dev Med Child Neurol 2013;55(6):509-19.

2. Panteliadis $C$, Panteliadis $P$, Vassilyadi F. Hallmarks in the history of cerebral palsy: from antiquity to mid-20th century. Brain Dev 2013;35(4):285-92.

3. Newman BM, Newman PR. Development Through Life: A Psychosocial Approach. Homewood, IL: Dorsey ; 1975

4. Hirsh A. Symptom burden in individuals with cerebral palsy. J Rehabil Dev 2010;47(9):863-76.

5. Ruth K. Cerebral Palsy. In Barnes MP, Good DC (eds). Handbook of Clinical Neurology. Elsevier Publications ;pp. 443-59.

6. Yarnell J. Epidemiology and Disease Prevention: A Global Approach (02ed.). Oxford University Press : London ; 2013.

7. Cerebral Palsy: Hope Through Research. National Institute of Neurological Disorders and Stroke (U.S.). NIH Publication No. 13-159. August 2013.

8. Stanley F, Blair E, Alberman E. Cerebral Palsies: Epidemiology and Causal Pathways. London, United Kingdom: MacKeith Press; 2000.

9. Rosenbaum P, Paneth N, Leviton A, Goldstein M, Bax M, Damiano D, Dan B, Jacobsson B. A report: The definition and classification of cerebral palsy. Dev Med Child Neurol 2006;49(4):8-10.

10. Palisano R. Development and reliability of a system, to classify gross motor function in children with cerebral palsy. Dev Med Child Neurol1997;39(2):214-23.

11. McKearnan KA, Kieckhefer GM, Engel JM, Jensen MP, Labyak S. Pain in children with cerebral palsy : a review. J Neuro Nurs 2011;26(5):252-9.

12. Smith ER, Mackie DM. Social Psychology ( $3^{\text {rd }}$ edn.). Hove: Psychology Press; 2007.

13. Hewitt JP. Oxford Handbook of Positive Psychology. Oxford University Press : London ; 2009.

14. Baumeister RF, Campbell JD, Krueger JI, Vohs KD. Does high self-esteem cause better performance, interpersonal success, happiness, or healthier lifestyles? Psychol Sci Pub Int $2003 ; 4(1): 1-44$.

15. Maslow AH. Motivation and Personality ( $3^{\text {rd }}$ edn.). New York: Harper \&Row ; 1987.

16. Gregory D, Johnston R, Pratt G, Watts M. Dictionary of Human Geography (5th ed.). Oxford:Wiley Blackwell ; 2009.

17. Kahneman D, Deaton A. High income improves evaluation of life but not emotional wellbeing. Proc Natl Acad Sci 2009;107(38):16489-93.

18. Magill J. Are families with adolescents and young adults with cerebral palsy the same as other families? Dev Med Child Neurol 2001;43(7):466-72.

19. Ellis A. The Myth of Self-esteem. Amherst, NY: Prometheus Books ; 2005.

20. Manuel JC, Balkrishnan R, Camacho F, Smith BP, Koman LA. Factors associated with selfesteem in pre-adolescents and adolescents with cerebral palsy.J Adolesc Health 2003;32(6):456-8.

21. Russo RN, Goodwin EJ, Miller MD, Haan EA, Connell TM, Crotty M. Self-esteem, selfconcept, and quality of life in children with hemiplegic cerebral palsy. J Pediatr $2008 ; 153(4): 473-7$.

22. Schmitt DP, Allik J. Simultaneous administration of the Rosenberg Self-Esteem Scale in 53 nations: exploring the universal and culture-specific features of global self-esteem. J Personal Soc Psychol 2005;89(4):623-9.

23. WHOQOL Group. Development of the World Health Organization WHOQOL-BREF quality of life assessment. Psychol Med 1998;28(3):551-8.

24. Shields N, Murdoch A, Loy Y, Dodd KJ, Taylor NF. A systematic review of the self-concept of children with cerebral palsy compared with children without disability. Dev Med Child Neurol 2006;48(2):151-7. 
Acknowledgements - Nil

Conflict of Interest - Nil

Funding - Nil.

\section{THANK YOU TO ALL OUR REVIEWERS - 2015}

A journal is able to maintain its standard and level of publishing due to its reviewers who guide the editor in many ways with regard to acceptance and rejection of manuscripts. The reviewer's job is a painstaking one and is a lot of time is devoted to enhance scientific publishing at no personal gain to the reviewer.

Indian Journal of Mental Health wishes to thank its reviewers for the year 2014

$$
\begin{gathered}
\text { Dr. Nilesh Shah (Mumbai) } \\
\text { Dr. Avinash De Sousa (Mumbai) } \\
\text { Dr. Cicilia Chettiar (Mumbai) } \\
\text { Dr. Sushma Sonavane (Mumbai) } \\
\text { Dr. Sagar Karia (Mumbai) } \\
\text { Mrs. Anuja Deshpande (Mumbai) } \\
\text { Dr. Anup Bharati (Mumbai) } \\
\text { Dr. Vishakha Shinde (Mumbai) } \\
\text { Dr. R. Parmeswaran (Coimbatore) } \\
\text { Mrs. Nazema Sagi (Mumbai) } \\
\text { Dr. Devavrat Harshe (Kolhapur) }
\end{gathered}
$$

